\title{
COVID-19 E OS IMPACTOS NA INDÚSTRIA PETROLÍFERA: CONSIDERAÇÕES INICIAIS
}

Rafael Almeida Ferreira Abrão'

\section{SINOPSE}

Este artigo tem como objetivo analisar os impactos iniciais da Covid-19 nos mercados globais de petróleo. A atual conjuntura possui a particularidade de apresentar alterações de mercado tanto na demanda, por efeitos das medidas de contenção da crise sanitária global, quanto na oferta, como resultado das disputas entre grandes produtores de petróleo, em particular Arábia Saudita e Rússia. Considera-se que os efeitos da pandemia podem resultar em profundas transformações para o setor petrolífero e a economia mundial, a depender da duração e dos desdobramentos da crise.

Palavras-chave: Covid-19; energia; petróleo.

\begin{abstract}
This article analyzes the initial impacts of Covid-19 on global oil markets. The current situation has the particularity of presenting market changes both in demand, due to the measures to contain the global health crisis, and in supply, as a result of the disputes between large oil producers, in particular Saudi Arabia and Russia. It is considered that the effects of the pandemic may result in profound changes for the oil sector and the world economy, depending on the duration and developments of the crisis.
\end{abstract}

Keywords: Covid-19; energy; oil politics.

JEL: Q4.

Artigo recebido em 28/6/2020 e aprovado em 30/6/2020.

DOI: http://dx.doi.org/10.38116/bepi27art1

\section{INTRODUÇÃO}

A energia é estratégica e essencial para a economia mundial. O funcionamento e a organização da sociedade industrial atribuíram-lhe uma centralidade política e econômica que moldou as relaçôes interestatais a partir do século XX e, entre todas as fontes de energia, o petróleo adquiriu o papel de maior relevância. A dinâmica da indústria petrolífera é dominada por incertezas relacionadas à volatilidade dos preços, à complexidade de prever conflitos e ao tempo de maturação dos projetos, dificultando projeçôes de médio e longo prazos. Tais incertezas foram agravadas pela pandemia de Covid-19 e seus efeitos sobre o mercado mundial, conforme se pôde observar com a queda abrupta dos preços após a paralisia das atividades e na retração econômica global. As análises se dividiram entre a possível retomada do funcionamento do setor sem grandes mudanças e a expectativa de profundas transformaçôes.

Em contraste com choques anteriores, a crise provocada pela Covid-19 pode não ser um fenômeno conjuntural, resultando em efeitos estruturais e de longo prazo. De acordo com Klare (2020), a

1. Doutorando em economia política mundial pela Universidade Federal do ABC (UFABC).E-mail: <ra.abrao@gmail.com>. 
transição energética para fontes mais limpas de energia tende a ser acelerada, e a demanda por petróleo pode não retornar aos patamares anteriores como efeito da difusão de hábitos de trabalho remoto, teleconferências, comércio virtual e ensino à distância. Em contraste com essa visão, Victor (2020) ressalta o papel decisivo do petróleo e de combustíveis derivados para a retomada da economia no mundo pós-pandemia. Segundo a análise do autor, após o fim das restriçôes, a populaçáo estará ávida para retomar seus hábitos, reforçando o modelo de dependência de combustíveis fósseis e recuperando os patamares de consumo de petróleo precedentes à crise.

A respeito dessa discussão, ainda é cedo para afirmar qual das tendências citadas prevalecerá. De todo modo, cabe destacar que: $i$ ) a transição energética exigiria a realização de altos investimentos, e o contexto de recessão econômica tende a inibi-los; ii) a influência política das empresas petrolíferas é utilizada para limitar a agenda ambiental; iii) a queda no preço do petróleo favorece o seu consumo e reduz as vantagens econômicas de fontes renováveis; e iv) a recuperação da economia dependerá do crescimento de países do sul global, o que implica um aumento da demanda por energia, particularmente em grandes mercados como Índia e China, que possuem matrizes altamente dependentes de hidrocarbonetos (petróleo, carvão e gás natural).

Os esforços para diminuir a velocidade de transmissão do vírus e evitar o colapso dos sistemas de saúde basearam-se na redução do contato social. Apesar das restriçóes de deslocamento, os fluxos internacionais de mercadorias e pessoas contribuíram para a disseminação do vírus para outras regiốes e para o número crescente de casos de Covid-19 ao redor do mundo (OMS, 2020). A característica da crise de saúde global rapidamente tomou contornos econômicos e resultou em graves impactos sobre a economia mundial e o uso de energia. Uma das principais instituiçôes do setor, a Agência Internacional de Energia (AIE), destacou o caráter disruptivo da pandemia, classificando-a como o maior choque no sistema energético global da história, podendo ter um impacto sete vezes superior ao da crise financeira internacional de 2008: $50 \%$ do uso mundial de energia foi afetado por medidas de contenção da Covid-19 (AIE, 2020a), e a contração da demanda e dos preços internacionais pode resultar em uma queda de $20 \%$ nos investimentos em energia (AIE, 2020b).

A pandemia de Covid-19 tornou a dinâmica inerentemente incerta da indústria petrolífera em um cenário ainda mais complexo e desafiador, o que resulta na necessidade de compreensão do contexto atual. Este artigo tem como objetivo analisar os impactos iniciais da Covid-19 nos mercados globais de petróleo, considerando-se que esses podem resultar em profundas transformaçóes para o setor e a economia mundial.

\section{IMPACTOS DOS ESFORÇOS DE CONTENÇÃO DA COVID-19}

A maior parte dos choques sofridos pela indústria petrolífera em sua história teve em sua origem desequilíbrios de oferta. No entanto, o atual cenário possui a particularidade de ser caracterizado por alteraçóes tanto de oferta quanto de demanda. Por um lado, ocorre a contraçáo do consumo por efeito das medidas de controle da Covid-19 e, por outro, há o excesso de oferta no mercado decorrente do aumento da produçáo na América do Norte e de disputas entre grandes produtores, como Rússia e Arábia Saudita. A combinaçáo de ambos os choques desenha um cenário sem precedentes para o setor, gerando incertezas quanto à abrangência e à duração da crise, além da expectativa de que os preços se mantenham reduzidos em meio à corrosão da demanda e à superoferta de petróleo (Ashraf, Satapathy e Chidambaram, 2020). 
Enquanto a demanda global de energia teve uma contração de 3,8\% no primeiro quadrimestre de 2020 em relação ao ano anterior, a maior queda nos últimos setenta anos, a demanda de petróleo foi atingida mais duramente, registrando uma queda de 5\% no mesmo período, e gerando uma expectativa de reduçáo de $9 \%$ na projeçáo para todo o ano. Esse efeito é resultado especialmente da diminuiçáo nos deslocamentos de veículos (-50\%) e na aviaçáo (-60\%), que somam $57 \%$ da demanda global por petróleo (AIE, 2020a). De acordo com IATA (2020), a receita com passageiros teve uma queda de $91,3 \%$ em abril de 2020 em comparação com o ano anterior, enquanto a ocupação de assentos apresentou uma contraçáo de $87 \%$ no mesmo período, impulsionada pelo fechamento de fronteiras. Globalmente, os combustíveis de aviação foram os derivados do petróleo com maior contraçáo da demanda, registrando quedas de $4 \%$ em janeiro, $14 \%$ em fevereiro e $27 \%$ em março, na comparaçáo com 2019. Nos Estados Unidos, as viagens aéreas tiveram uma queda de $95 \% \mathrm{em}$ abril em relação ao ano anterior, o que pode ocasionar uma recuperaçáo lenta, considerando que a população está receosa quanto à retomada de voos (Air travel..., 2020).

A AIE (2020a) estima que a recuperação dos níveis anteriores de consumo ocorra gradualmente, com a progressiva suspensão das políticas de contenção da pandemia e a retomada dos níveis de atividade econômica. A projeçáo é que a demanda no primeiro quadrimestre de 2020 seja 29 milhóes de barris por dia (mb/d) abaixo dos níveis registrados em 2019, e a recuperação dos níveis anteriores à crise aconteça somente em 2021. Na China, o primeiro país afetado pela Covid-19 e o maior importador de petróleo bruto e produtos derivados, registrou-se queda de $13 \%$ na demanda por petróleo e contração de $33 \%$ na demanda de gasolina e de $28 \%$ na de querosene de aviaçáo, no primeiro quadrimestre de 2020 em comparação com o ano anterior. Em maio, enquanto outras partes do mundo continuaram a registrar queda na demanda, a China deu sinais de resiliência e se consolidou como o principal centro de consumo mundial. As importaçóes de petróleo cresceram 19,2\% em relação ao mesmo mês do ano anterior, alcançando 11,3 mb/d (Chen et al., 2020), uma expansão que analistas relacionam com a recuperação da demanda por petróleo e, em menor grau, por refinarias chinesas estarem aproveitando a queda nos preços internacionais do petróleo, aumentando seus estoques e temendo futuras restriçôes decorrentes da guerra comercial entre China e Estados Unidos (Paraskova, 2020).

De acordo com o departamento energético dos Estados Unidos (EIA, 2020b), à medida que as políticas de isolamento e distanciamento social tiveram efeito no país, a demanda de petróleo e derivados entrou em declínio, especialmente no caso dos combustíveis ligados aos deslocamentos e às viagens individuais. A demanda de gasolina, utilizada em veículos de passageiros, deve ser mais afetada que o diesel, uma vez que este é amplamente utilizado no transporte de cargas e no setor manufatureiro. Entre fevereiro e março, a demanda de gasolina nos Estados Unidos teve uma queda de 13\%, sendo reduzida ao menor nível desde janeiro de 2000 (1,2 mb/d). No mesmo período, a demanda de combustíveis para aviação apresentou uma contração de 15\%, a maior queda registrada pela série histórica iniciada em 1965. Os combustíveis destilados foram menos afetados em virtude do seu uso em atividades econômicas essenciais - como motores a diesel de equipamentos de construçáo e óleo de aquecimento utilizado por residências e indústrias -, com uma queda de $2 \%$ no primeiro trimestre. A reduçáo do consumo limitou as operaçôes de refino, que registraram uma contração de 4\% nacionalmente (chegando a 10\% nas refinarias da costa oeste), e provocou o aumento de $6 \%$ nos estoques de petróleo bruto.

O número de plataformas de petróleo e gás natural ativas nos Estados Unidos atingiu o menor patamar desde 1987, ano em que a série histórica começou a ser contabilizada, com uma queda de 
56\% entre março e maio de 2020 (EIA, 2020a). Projeçôes para o final de 2020 revelam que as medidas de mitigação da Covid-19 resultarão em uma redução média de $0,5 \mathrm{mb} / \mathrm{d}$ na produção de petróleo em relação a 2019, contraindo-se de $12,3 \mathrm{mb} / \mathrm{d}$ para $11,7 \mathrm{mb} / \mathrm{d}$ (EIA, 2020b). Ainda de acordo com dados do departamento estadunidense, ilustrados no gráfico 1, o consumo mundial de petróleo e líquidos derivados em dezembro de 2019 foi de 101,86 mb/d, e a previsão era de expansão em 2020. A contração levou o consumo mundial a $79,15 \mathrm{mb} / \mathrm{d}$, o que significa uma redução de $22,29 \% \mathrm{em}$ 2020 em relação ao ano anterior (EIA, 2020b), uma oscilação que pode ser observada no gráfico 1 .

\section{GRÁFICO 1}

\section{Produção e consumo mundial de petróleo}

(Em mb/d)

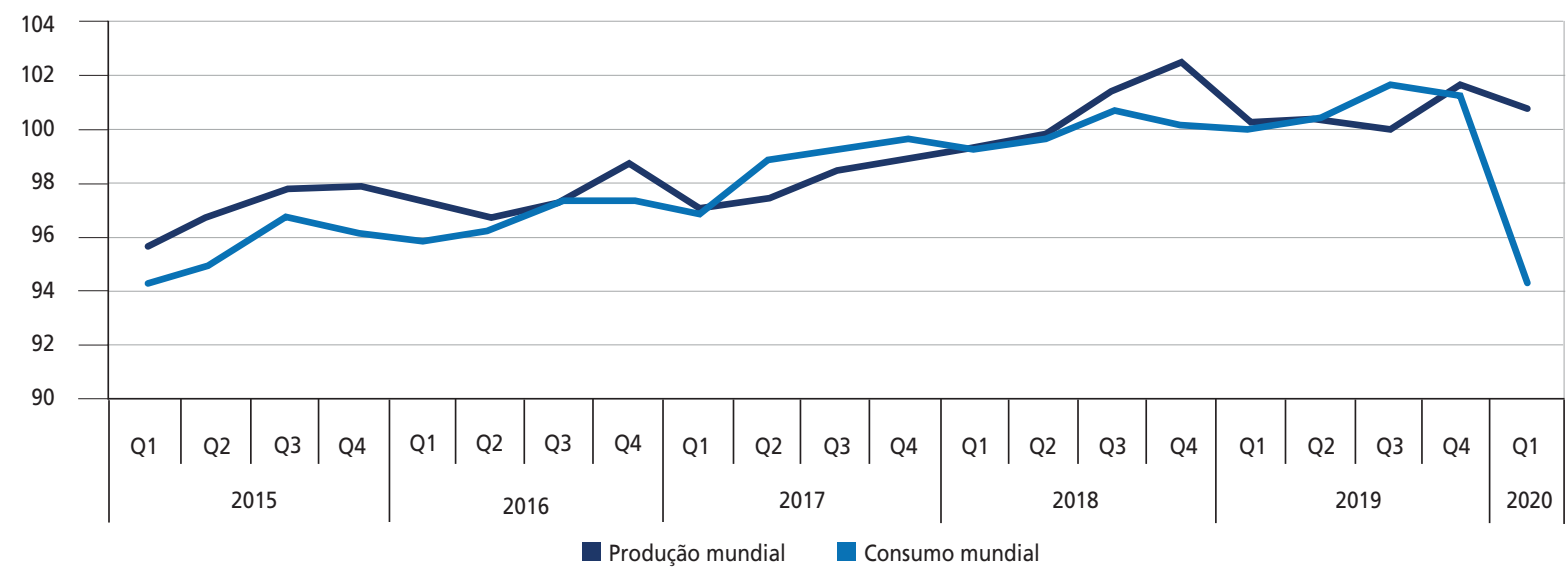

Fonte: EIA (2020b).

Obs.: Q - quadrimestre.

Observa-se que o movimento de queda abrupta da demanda náo foi acompanhado pelos produtores. Em dezembro de 2019, a produçáo mundial foi de $101,73 \mathrm{mb} / \mathrm{d}$, um número que se manteve praticamente estável até abril, sustentando-se em 100,64 mb/d naquele mês, quando a demanda já estava abaixo do patamar de $80 \mathrm{mb} / \mathrm{d}$. A redução atrasada para $89,58 \mathrm{mb} / \mathrm{d}$, e ainda insuficiente, ocorreu apenas em maio (EIA, 2020b). Isso se deve ao fato de que, para além dos efeitos da pandemia, os mercados foram saturados pela guerra de preços entre países produtores, destacadamente Arábia Saudita e Rússia, com o objetivo de ganhar participação no mercado e quebrar outros produtores que possuem maior custo de produção (Yergin, 2020). Diante do cenário de forte contração do consumo de petróleo e derivados, a reação de países produtores agravou os desequilíbrios entre oferta e demanda. Os onze produtores da Organização dos Países Exportadores de Petróleo (OPEP) e outros dez países, o que ficou conhecido como OPEP+, não conseguiram acordar uma redução da produção. Entre os dois principais produtores, a Rússia buscava a manutenção dos níveis de produção existentes e a Arábia Saudita defendia cortes para evitar um declínio acentuado dos preços. Em 6 de março de 2020, ambos passaram a atuar de forma independente, indicando o rompimento na cooperaçáo existente no âmbito da OPEP+ (O'Sullivan, 2020), e, em meio à queda na demanda mundial, aumentaram significativamente a produção.

Com a instabilidade nos preços, os Estados Unidos se empenharam para que cortes fossem feitos por Arábia Saudita, Rússia e outros produtores, como Canadá e México, na tentativa de conter o declínio dos preços e estabilizar o mercado (Yergin, 2020). Os países da OPEP+ chegaram a um 
acordo apenas em 12 de abril, após perceberem a extensão da crise e os impactos da pandemia sobre a indústria, comprometendo-se com um corte de $9,7 \mathrm{mb} / \mathrm{d}$ entre maio de 2020 e abril de 2022, o que não foi suficiente para sanar os desequilíbrios dos mercados, que, como consequência, apresentaram extrema volatilidade em abril.

Nos Estados Unidos, a capacidade de estocagem foi comprometida pelo excesso de importaçóes e da produção interna. Os detentores de contratos de West Texas Intermediate (WTI) na New York Mercantille Exchange (NYMEX) tiveram que pagar taxas acima do comum, o que criou o raro efeito de preços negativos no mercado, ou seja, os investidores estavam pagando aos produtores para encerrar o contrato antes da data de expiração a fim de tentar cumprir os compromissos estabelecidos (EIA, 2020c). Os contratos de WTI, referentes a maio e que expirariam em 21 de abril, chegaram a ser cotados no valor negativo de US\$ 40,32 por barril, fechando a US\$ -37,63 no dia 20 daquele mês, fato inédito na história do petróleo. No passado, preços negativos haviam sido registrados em relação à cotação de outras commodities, em geral, por custos elevados de transação ou restriçôes na infraestrutura, mas isso nunca ocorrera com o preço de referência de um barril de petróleo. O preço negativo significou que detentores de contratos futuros passaram a pagar produtores para estocar a mercadoria diante da dificuldade de achar compradores para evitar a liquidaçáo dos contratos (EIA, 2020b; 2020c).

A contração nas cotações do barril de petróleo, as distorçôes na dinâmica entre oferta e demanda e as incertezas acerca dos desdobramentos da pandemia têm alterado o nível de atividade da indústria e provocado a revisão de investimentos. O tradicional relatório produzido por Baker Hughes (2020) a respeito das sondas de perfuração de petróleo ativas registrou uma queda de atividade de $71,2 \%$ nos Estados Unidos, $80,4 \%$ no Canadá e $28,5 \%$ no restante do mundo, comparando os meses de maio de 2020 e 2019, sendo este um indicador do impacto abrangente que a pandemia de Covid-19 está provocando sobre a demanda de equipamentos utilizados pela indústria petrolífera e seus fornecedores. As despesas de capital em projetos existentes e nas cadeias de suprimentos foram restringidas, criando o risco de cortes de trabalhadores em projetos onshore e offshore, dificultando a movimentação de pessoas entre os países onde as empresas operam e provocando interrupçóes no fornecimento de materiais e equipamentos. Exemplo disso é a região da Lombardia, na Itália, uma das principais áreas de engenharia de equipamentos de petróleo e que foi duramente afetada pela pandemia. Além disso, das 28 plataformas flutuantes em produçáo no primeiro quadrimestre de 2020, 22 estavam sendo construídas em estaleiros na China, na Coreia do Sul e em Singapura, países que tiveram suas atividades industriais restringidas. Cabe ainda destacar que os leilóes de petróleo foram suspensos em Bangladesh, Brasil, Índia, Libéria, Senegal, Sudão do Sul, Tailândia e Reino Unido (AIE, 2020b).

A impossibilidade de os consumidores aproveitarem a queda nos preços dos derivados do petróleo colocou a pressáo do ajuste totalmente sobre a oferta, levando à necessidade de interrupção de parte da produção existente e ao acúmulo de estoques, intensificando a queda nos preços do barril. As empresas responderam revisando os investimentos programados, que já haviam sido revistos em anos anteriores. Entre 2014 e 2019, houve um corte de 40\% nos investimentos e, até o momento, os anúncios revelam que a pandemia pode resultar em uma redução adicional de $25 \%$ nos aportes (AIE, 2020b). 
TABELA 1

Investimentos em petróleo (2015-2020)

(Em US\$ bilhões)

\begin{tabular}{|c|c|c|c|c|c|c|}
\hline Região & 2015 & 2016 & 2017 & 2018 & 2019 & 2020 \\
\hline América do Norte & 161 & 130 & 151 & 161 & 151 & 97 \\
\hline América do Sul e Central & 49 & 36 & 37 & 43 & 46 & 31 \\
\hline Europa & 49 & 34 & 37 & 39 & 40 & 28 \\
\hline Eurásia & 55 & 44 & 42 & 40 & 37 & 26 \\
\hline Ásia/Pacífico & 76 & 66 & 69 & 76 & 76 & 53 \\
\hline
\end{tabular}

Fonte: AIE (2020b).

Os investimentos realizados em exploração e desenvolvimento de petróleo e gás por 102 empresas de petróleo com capital aberto ${ }^{2}$ somaram US\$ 361 bilhóes em 2019, registrando um acréscimo de 13\% em relação ao ano anterior (EIA, 2020d). Deste montante, 37\% dos investimentos foram realizados nos Estados Unidos, 25\% na Rússia, na Ásia Central e no Pacífico e 13\% na América Latina (EIA, 2020e). A crise tende a afetar mais severamente três partes da indústria: $i)$ pequenas e médias companhias estadunidenses, especialmente as envolvidas na exploração de xisto; ii) estatais de alguns países que dependem severamente da renda oriunda da exploração de petróleo; e iii) empresas de serviços que têm sofrido o impacto dos cortes nas despesas de capital. Para se adaptar à queda na demanda e ao cenário de preços reduzidos, algumas companhias estatais anunciaram cortes em suas despesas, como a saudita Saudi Aramco (25\%), a brasileira Petrobras (30\%), a chinesa PetroChina (30\%) e a argelina Sonatrach (50\%). Espera-se ainda o agravamento da situaçáo de estatais que apresentavam um desempenho insatisfatório antes da crise, como a angolana Sonangol e a venezuelana PDVSA (AIE, 2020b).

Como resultado do declínio dos preços do petróleo, poderá ocorrer ainda um decréscimo das reservas mundiais economicamente recuperáveis e dos investimentos previstos em exploração e desenvolvimento. As companhias terão que fazer impairments, ou seja, uma revisão dos valores dos ativos que possuem, de acordo com a oscilação dos preços e a quantidade técnica e economicamente recuperável de suas reservas (EIA, 2020e), o que resultará em um cenário difícil para países que estavam realizando investimentos na exploraçáo de novas reservas, uma vez que, segundo estudo de Rystad Energy (2020), há indícios de que atingiremos o pico da demanda de petróleo, e parte dos recursos mundiais continuará intocada. Estima-se que 282 bilhôes de barris deixarão de ser economicamente viáveis, uma redução que ocorrerá especialmente em países de fora da OPEP. O relatório de Rystad Energy (2020) aponta ainda uma queda de 49 bilhóes nas reservas dos Estados Unidos, em particular nos reservatórios de xisto e do Golfo do México, de 31 bilhôes na Rússia, reduzindo a atratividade do Ártico, de 21 bilhôes na Venezuela, de 15 bilhóes no Brasil, com uma parte do pré-sal sendo mantida intacta, de 14 bilhóes no México, atingindo a exploração de xisto e em águas profundas, e de 14 bilhōes de barris no Canadá, nas areias betuminosas. Esse cenário tende a favorecer os produtores de recursos com custos reduzidos de produção, como Arábia Saudita, Iraque e Kuwait.

No entanto, de acordo com FMI (2020), a maioria dos principais produtores de petróleo, com exceção do Catar, necessita de preços acima de US\$ 60 por barril para equilibrar seus orçamentos

2. Entre as 102 empresas incluídas nos levantamentos estão companhias latino-americanas, como Ecopetrol, Petrobras, Pemex e YPF, e grandes companhias transnacionais, como British Petroleum (BP), Chevron, Equinor, ExxonMobil, PetroChina, Repsol, Shell e Sinopec. 
(fiscal breakeven oil price), o que gera grandes expectativas sobre as consequências políticas que as restriçóes de capital podem ocasionar, considerando que os preços já estavam em um patamar reduzido desde 2014. Além disso, conforme destacado por Blackwill e Harris (2016), cada país possui uma capacidade única para lidar com a contração dos preços internacionais, a depender da intensidade e da duração da queda, da estrutura e da diversificaçáo da sua economia, além das possibilidades políticas de implementar cortes em seu orçamento.

Na América Latina, Monaldi (2020) ressalta que $9 \%$ da produção se torna inviável com o preço a US\$ 35, montante que sobe para mais da metade da produçáo com o preço a US\$ 20 por barril. O colapso nos preços pode significar um alívio econômico para naçóes importadoras, especialmente no Caribe, e afetar negativamente as contas fiscais e externas de países da América do Sul, bem como de México e Trinidad e Tobago (OCDE, 2020). Os mais afetados devem ser aqueles países altamente dependentes da renda petrolífera, como Venezuela, Equador e Colômbia. Para Brasil e México, os maiores produtores da região, o impacto deve ser menor, em decorrência da diversificação de suas economias e do consumo interno de grande parte da sua produçáo, pois apenas uma parcela reduzida da produção de petróleo de ambos os países é destinada à exportação.

De todo modo, o estado do Rio de Janeiro, pelo declínio da arrecadação fiscal com royalties de petróleo, e a estatal Petróleos Mexicanos (Pemex), pelo alto endividamento da empresa antes do início da crise, devem ser duramente afetados. Segundo dados de ANP (2020), somente no Brasil a produção foi interrompida em 38 campos de petróleo, somando 66 instalaçōes marítimas, entre plataformas e embarcaçôes flutuantes, que suspenderam atividades no país. Quanto ao México, a Pemex era a empresa de petróleo mais endividada do mundo antes do início da crise, sendo que a sua dívida aumentou de US\$ 59 bilhôes, em 2012, para US\$ 105 bilhóes, em 2018 (Leiss e Duhalt, 2019, p. 3). A empresa não interrompeu suas operaçóes, apesar de 464 funcionários terem testado positivo para a doença, dos quais 55 perderam a vida por causa da Covid-19 (Pemex, 2020), reforçando críticas à empresa, que estaria ignorando a pandemia ao não interromper suas atividades (Stillman, 2020), e ao governo mexicano, por não atender aos apelos por cortes na produção no âmbito da OPEP+ (By ignoring..., 2020).

\section{CONSIDERAÇÕES FINAIS}

O petróleo está presente nas mais diversas atividades econômicas, de maneira que Daniel Yergin, em $O$ Petróleo, obra que se tornou referência no tema, o classificou como "a maior e mais problemática [fonte de energia] por causa de seu papel central, seu caráter estratégico" (Yergin, 1991, p. 780, tradução nossa). Sua história é repleta de crises, guerras, revoluçôes, assassinatos, golpes de Estado e outros episódios relevantes relacionados às disputas entre diversos atores internacionais para se apropriar de suas riquezas, e observa-se que, por continuar a ser essencial para o funcionamento da economia mundial, a competição pelos valores que produz permanece evidente. Exemplo disso é a discordância entre importantes países produtores, destacadamente Arábia Saudita e Rússia, no âmbito da OPEP+, e suas consequências para a indústria em um contexto de redução do consumo mundial.

No atual cenário de crise, a recuperaçáo da economia depende de desdobramentos ainda imprevisíveis da pandemia, como a duraçáo das medidas de isolamento e distanciamento social. Para a indústria petrolífera, as tendências prevalecentes serão influenciadas pela velocidade da recuperação econômica, considerando que uma crise prolongada pode provocar uma profunda reestruturação, com produtores 
menores e ativos de maior custo ficando de fora do mercado, ou pelo fato de que um possível cenário de resolução da crise de saúde global nos próximos meses pode diminuir a abrangência dos efeitos sobre o setor. Há ainda a possibilidade de novas ondas de infecçôes no segundo semestre de 2020, levando a interrupçóes das atividades econômicas classificadas como náo essenciais, e impactos de difícil mensuração, como a aversão ao uso de transporte público, a restrição às viagens aéreas e a disseminação de hábitos de atividades não presenciais no mundo pós-pandemia. A indústria terá que se adaptar à possibilidade de uma lenta recuperação do consumo e ao cenário de preços reduzidos, de tal modo que somente empreendimentos que permanecerem rentáveis sobreviverão. Em suma, desenha-se um cenário de incertezas para investidores, produtores e empresas da cadeia produtiva de petróleo.

\section{REFERÊNCIAS}

AIE - AGÊNCIA INTERNACIONAL DE ENERGIA. Global energy review 2020. Paris: IEA, 2020a. Disponível em: <https://www.iea.org/reports/global-energy-review-2020>. Acesso em: 1o jun. 2020.

World energy investment 2020. Paris: IEA, 2020b. Disponível em: <https://www.iea.org/reports/ world-energy-investment-2020>. Acesso em: 30 maio 2020.

AIRTRAVEL drops nearly 95\% from 1 year ago amid pandemic. KTLA, Los Angeles, 8 Apr. 2020. Disponível em: <https:// ktla.com/news/nationworld/air-travel-drops-nearly-95-from-1-year-ago-amid-pandemic/>. Acesso em: 11 jun. 2020.

ANP - AGÊNCIA NACIONAL DE PETRÓLEO, GÁS NATURAL E BIOCOMBUTÍVEIS. Boletim da Produçáo de Petróleo e Gás Natural, n. 116, abr. 2020. Disponível em: <http://www.anp.gov.br/arquivos/ publicacoes/boletins-anp/producao/2020-04-boletim.pdf>. Acesso em: 24 jun. 2020.

ASHRAF, M.; SATAPATHY, M.; CHIDAMBARAM, V. The one-two punch for oil markets. Dublin: Accenture, 2020. Disponível em: <https://www.accenture.com/_acnmedia/PDF-121/Accenture-One-TwoPunch-For-Oil-Markets-Report.pdf>. Acesso em: 12 jun. 2020.

BAKER HUGHES. Rig count overview \& summary count. Baker Huges Rig Cout, Houston, 12 June 2020. Disponível em: <https://bakerhughesrigcount.gcs-web.com/rig-count-overview>. Acesso em: 13 jun. 2020.

BLACKWILL, R.; HARRIS, J. War by other means: geoeconomics and statecraft. Cambridge/Londres: Harvard University Press, 2016.

BY IGNORING the Covid-19 crisis and OPEC+ requests, Pemex puts Mexico's oil supply at risk. Offshore Technology, New York, 14 Apr. 2020. Disponível em: <https://www.offshore-technology.com/comment/ covid-19-crisis-opec-requests/>. Acesso em: 24 jun. 2020.

CHEN, Y. et al. China registra importação mensal recorde de petróleo em maio. Reuters, 8 jun. 2020. Disponível em: <https://br.reuters.com/article/businessNews/idBRKBN23F1CN-OBRBS>. Acesso em: 8 jun. 2020.

EIA - U.S. ENERGY INFORMATION ADMINISTRATION. The number of active U.S. crude oil and natural gas rigs is at the lowest point on record. EIA, Washington, 20 May 2020a. Disponível em: <https:// www.eia.gov/todayinenergy/detail.php?id=43796>. Acesso em: $1^{\circ}$ jun. 2020.

Short-term energy outlook. EIA, Washington, May 2020b. Disponível em: <https://www.eia.gov/ outlooks/steo/>. Acesso em: 6 jun. 2020.

. WTI crude oil futures prices fell below zero because of low liquidity and limited available storage. EIA, Washington, 22 Apr. 2020c. Disponível em: <https://www.eia.gov/petroleum/weekly/archive/2020/200422/ includes/analysis_print.php>. Acesso em: 8 jul. 2020.

Finance review 2019. EIA, Washington, 21 May 2020d. Disponível em: <https://www.eia.gov/ finance/review/pdf/financial_2019.pdf>. Acesso em: 6 jun. 2020. 
Lower crude oil prices will mean less exploration and development. EIA, Washington, 4 June 2020e. Disponível em: <https://www.eia.gov/todayinenergy/detail.php?id=43975>. Acesso em: 6 jun. 2020.

FMI - FUNDO MONETÁRIO INTERNACIONAL. Breakeven oil prices. IMF, 2020. Disponível em: <https://data.imf.org/regular.aspx?key=60214246>. Acesso em: 8 jun. 2020.

IATA - INTERNATIONAL AIR TRANSPORTATION ASSOCIATION. Air passenger market analysis. IATA, Apr. 2020 Disponível em: <https://www.iata.org/en/iata-repository/publications/economic-reports/ air-passenger-monthly-analysis---apr-20202/>. Acesso em: 9 jun. 2020.

KLARE, M. The beginning of the end for oil? Energy in a post-pandemic world. TomDispatch, 28 abr. 2020. Disponível em: <http://www.tomdispatch.com/post/176694/tomgram\%3A_michael_klare\%2C_a_silver_ lining_in_the_global_pandemic/>. Acesso em: 27 maio 2020.

LEISS, B. C.; DUHALT, A. Laying the groundwork for the strengthening of Pemex. Houston: Center for Energy Studies; Rice University's Baker Institute for Public Policy, July 2019.

MONALDI, F. Who the oil price collapse hurts most in Latin America? Americas Quartely, 29 Apr. 2020 Disponível em: <https://www.americasquarterly.org/article/who-the-oil-price-collapse-hurts-most-in-latinamerica/>. Acesso em: 11 jun. 2020.

OCDE - ORGANIZAÇÃO PARA A COOPERAÇÃO E O DESENVOLVIMENTO ECONÔMICO. Covid-19 in Latin America and the Caribbean. OCDE, Paris, 29 abr. 2020. Disponível em: <http://www. oecd.org/coronavirus/policy-responses/covid-19-in-latin-america-and-the-caribbean-regional-socio-economicimplications-and-policy-priorities-93a64fde/>. Acesso em: 15 jun. 2020.

OMS - ORGANIZAÇÃO MUNDIAL DA SAÚDE. Report of the WHO-China joint mission on coronavirus disease 2019 (Covid-19). WHO, Genebra, 28 Feb. 2020. Disponível em: <https://www.who.int/publications/i/ item/report-of-the-who-china-joint-mission-on-coronavirus-disease-2019-(covid-19)>. Acesso em: 8 jun. 2020.

O'SULLIVAN, M. Oil markets provide a glimpse of the post-pandemic future. Bloomberg, 7 Apr. 2020. Disponível em: <https://www.bloomberg.com/opinion/articles/2020-04-07/what-will-the-world-look-likeafter-covid-19-watch-oil-markets>. Acesso em: 11 jun. 2020.

PARASKOVA, T. The real reason China is importing so much oil. Oil Price, 9 June 2020. Disponível em: $<$ https://oilprice.com/Energy/Crude-Oil/The-Real-Reason-China-Is-Importing-So-Much-Oil.html>. Acesso em: 22 jun. 2020.

PEMEX - PETRÓLEOS MEXICANOS. Healthcare report of Pemex workers and patients affected by Covid-19. Pemex, 4 May 2020. (Press Release). Disponível em: <https://www.pemex.com/en/press_room/ press_releases/Paginas/2020_071-national.aspx>. Acesso em: 8 jul. 2020.

RYSTAD ENERGY. Annual review of world oil resources.Rystad Energy, 17 June 2020. (Press Release). Disponível em: <https://www.rystadenergy.com/newsevents/news/press-releases/rystad-energys-annual-reviewof-world-oil-resources-recoverable-oil-loses-282-billion-barrels-as-covid-19-hastens-peak-oil/>. Acesso em: 22 jun. 2020.

STILLMAN, A. Pemex's virus death toll soars higher than nurses in Mexico. Bloomberg, 15 May 2020. Disponível em: <https:/www.bloomberg.com/news/articles/2020-05-15/pemex-covid-19-death-toll-soarshigher-than-nurses-in-mexico>. Acesso em: 24 jun. 2020.

VICTOR, D. G. The pandemic won't save the climate. Foreign Affairs, 7 May 2020. Disponível em: <https:// www.foreignaffairs.com/articles/2020-05-07/pandemic-wont-save-climate>. Acesso em: 27 maio 2020.

YERGIN, D. The prize: the epic quest for oil, money and power. New York: Simon and Schuster, 1991.

. The oil collapse. Foreign Affairs, 2 Apr. 2020. Disponível em: <https://www.foreignaffairs.com/ articles/2020-04-02/oil-collapse>. Acesso em: 1o jun. 2020. 
